\title{
Soil Health Assessment Methods and Relationship with Wheat Yield
}

\author{
Jatish C. Biswas', Naveen Kalra², M. Maniruzzaman³, U. A. Naher ${ }^{3}$, M. M. Haque ${ }^{3 *}$ \\ ${ }^{1}$ Bangladesh Rice Research Institute \& Coordinator, KGF, Dhaka, Bangladesh \\ ${ }^{2}$ Indian Agricultural Research Institute, New Delhi, India \\ ${ }^{3}$ Bangladesh Rice Research Institute, Gazipur, Bangladesh \\ Email: *mhaquesoil@yahoo.com
}

How to cite this paper: Biswas, J.C., Kalra, N., Maniruzzaman, M., Naher, U.A. and Haque, M.M. (2019) Soil Health Assessment Methods and Relationship with Wheat Yield. Open Journal of Soil Science, 9, 189-205.

https://doi.org/10.4236/ojss.2019.99011

Received: July 18, 2019

Accepted: September 24, 2019

Published: September 27, 2019

Copyright (c) 2019 by author(s) and Scientific Research Publishing Inc. This work is licensed under the Creative Commons Attribution International License (CC BY 4.0).

http://creativecommons.org/licenses/by/4.0/

\begin{abstract}
Soil quality assessment methods, based on different attributes, are available but not well calibrated/validated for subsequent operational applications. We have developed a method for soil quality index assessment by considering soil texture, organic carbon, $\mathrm{pH}$, available water, cation exchange capacity, bulk density, total porosity, saturated hydraulic conductivity, salinity, aggregate stability, slope and soil depth. The scoring was done on 0 - 100 scale and the lowest score was assigned to the most limiting factor of crop growth and development. Attribute-wise rating was made by using Macros developed in MS-Excel and IDRISI3.2 was used to delineate the rating maps. About $64.6 \%$ soils scored more than 60 and the best soil group (score $>70$ ) was only about $15 \%$. Soil health score, as determined through our method, showed good relationship with wheat yield. Multiplicative response function was more sensitive than simple regression model. The correlation analyses with one or two attributes with most severe stress and relatively with lower rating values showed better predictability of wheat yields. The soil quality index as estimated from principal component analysis having strongly loaded $(>0.75)$ factors showed inferior correlation with grain yields of wheat than geometric mean approach. It is concluded that geometric mean approach for soil health scoring can be utilized in similar environments around the globe with or without further improvement.
\end{abstract}

\section{Keywords}

Soil Quality, Additive and Multiplicative Function, PCA, Minimum Data

\section{Introduction}

Soil health is the basic requirement to produce quality food for consumption. 
Different physical, chemical and biological properties are considered either quantitatively or qualitatively to determine soil health. Parameters that are easy to measure and sensitive to management options indicate good soil quality indicators. Generally, soil pH, surface hardness, aggregate stability, soil organic carbon (SOC), cation exchange capacity (CEC), crop residues, earthworms, soil depth, slope, etc. can be utilized for soil quality index (SQI) determination. It is typically achieved using a modeling framework, which can broadly be divided into function- and process-based analyses. Many approaches like Cornell's approach [1], Wisconsin Soil Health Score Card, Illinois Soil Quality Initiative, Radar Diagram, Ohio Soil Health Card [2], Agroeco-system Performance Assessment Tool, Soil Conditioning Index, Soil Management Assessment Framework [3], etc. are found in the literature having different complexities and inadequacies. As the steps of mechanistic processes are seldom calibrated and described, the proposal for direct estimates of soil quality from indicator data through process-based approach, without the use of empirical weighting factors or functional equations, is often very difficult to achieve. Some of the important approaches for function-based model are productivity index [4], SQI [5] and scoring functions [6].

Most research on quality assessment are based on surface soil dynamic properties data [7] [8] [9] [10] that do not reflect sub-surface characters for proper crop production and managements to be adopted [11]. A long list of items has been selected to evaluate SQI, but not considered soil depth and slope in many cases. Slope plays an important role in degrading soil quality and thus special management is needed to recuperate it. Vasu et al. [12] reported a good relationship of SQI with soil function when subsurface properties were included with surface dynamic ones; but Mukherjee and Lal [13] found no variation with sub-surface properties. However, they have not considered whole country, a gigantic task for a nation to be accomplished.

Soil amendment in association with crop production is an inevitable part of agriculture, and thus changes in its nature take place over time. To utilize soil potential sustainably, the determination of SQI, though not simple, is essential. Old methods for SQI assessment were mostly based on qualitative and quantitative parameters [14] [15] [16], but it requires quantitative index for agricultural land suitability assessment [12] [17] [18]. Therefore, SQI has a greater significance for sustainable use of soil in crop production. One can use simple additive, weighted additive and statistically modeled derived SQI, because no standard method yet is established. Mukherjee and Lal [13] reported suitability of statistical based principal component analysis (PCA) for SQI determination. We hypothesize that a combination of multiplicative model and logic based scoring for SQI might be beneficial for soil health quality scoring.

Bangladesh, a deltaic country, is heavily pressurizing its soil resources for more production in one hand and on the other, climate change impacts are adding additional burden to natural resources through salinization because of sea level rise, reduced upstream flow, increasing acidity through diminishing ba- 
sic cations, etc. In a small country, like Bangladesh, there are many soils with plenty of potentials and limitations; but unfortunately no SQI is available for its proper management and sustainable crop production to feed about 160 million peoples. This scenario is also true for many developing countries of the world. Therefore, we have taken an initiative to develop SQI for Bangladesh, which can also be utilized for other similar environments of the globe.

\section{Material and Methods}

In the present investigation, the attributes considered for soil health scoring are texture, soil organic carbon (SOC), soil $\mathrm{pH}$, soil available water, cation exchange capacity (CEC), bulk density (BD) for clayey and non-clayey soils, porosity, saturated hydraulic conductivity (Ks), soil salinity, soil aggregate stability (WDCS), slope, and soil depth. In selecting data from available sources, expert judgement, crop performance, soil complexity and functions were considered [10] [12]. Data were collected from Bangladesh Agricultural Research Council, Soil Resource Development Institute and published literatures during 2010-2018 considering 64 districts of Bangladesh. Attribute-wise ratings over different locations of Bangladesh were made by using interpolation technique (using MS-Excel Macros and IDRISI3.2). Delineation maps of attribute-wise rating were prepared by using IDRISI3.2. Development of soil health rating map was accomplished by integrating multiplicative, model, and logic and finally following geometric means approach. Direct measured data on soil $\mathrm{pH}$, soil texture, CEC $\left(\mathrm{cmol}_{\mathrm{c}} \cdot \mathrm{kg}^{-1}\right)$, SOC (\%), soil depth ( $\left.\mathrm{cm}\right)$, slope (\%), soil salinity $\left(\mathrm{dS} \cdot \mathrm{m}^{-1}\right)$ and drainage were used. Others were computed following standard protocols.

Field capacity (FC), wilting point and Ks was derived by using decision support system for agro-technology transfer (DSSAT) inbuilt transfer functions using sand, silt, clay and SOC. Adhikary et al. [19] also used pedo-transfer functions for predicting hydraulic properties of Indian soils. Computed FC and DSSAT inbuilt FC showed very close relationship $\left(y=0.922 x+0.029 ; R^{2}=\right.$ $0.922)$. The permanent wilting point (PWP) was estimated as following equation

$$
y=-5 \mathrm{E}-05 x^{2}+0.007 x+0.019 ; R^{2}=0.898
$$

where, $y$ is the PWP (vol. fraction) and $x$ is the \% clay

The inter-relationships of $\mathrm{BD}, \mathrm{FC}$, wilting point, available water, total porosity, macro-porosity, and Ks were established with percent clay contents. Soil available water was considered as the difference between FC and PWP. With regard to computed some of the soil physical constants, pedo-transfer functions as developed by Kalra et al. [20] for Indian soils were also evaluated because of its similarities with Bangladesh.

\subsection{Water Dispersible Soil Aggregate Stability Index}

From our long term trial at Bangladesh Rice Research Institute, Gazipur, we have found $7.02-7.66$ mean weight diameter $(\mathrm{mm})$ aggregate size from silty clay soil (Haque et al., [21]), which was close to the findings (7.41 - 11.28) of Sung, 
[22] having similar clay fractions. In our case, soil samples were very limited, so we have determined WDCS by the following equation adopted from Sung [22] as follows:

$$
y=9.306508+1.157381 \mathrm{Silt}(\%)+0.150741 \mathrm{Sand}(\%) ; R^{2}=0.4413
$$

where, $y$ is the WDCS index.

\subsection{Bulk Density (Mg· $\left.\mathrm{m}^{-3}\right)$}

It was determined through pedo-transfer function as

$$
y=-0.09 \ln (x)+1.605, R^{2}=0.502
$$

where, $y$ is the bulk density in $\mathrm{Mg} \cdot \mathrm{m}^{-3}, x$ is the $\%$ clay content.

\subsection{Soil Available Water Content (Volume Fraction)}

It was determined by subtracting PWP from FC.

\subsection{Total Porosity (Volume Fraction)}

It was determined as per following equation

$$
y=0.403 x^{0.066}, R^{2}=0.526
$$

where, $y$ is the total porosity and $x$ is the $\%$ clay content.

\subsection{Saturated Hydraulic Conductivity $\left(\mathrm{cm} \cdot \mathrm{hr}^{-1}\right)$}

It was estimated as per following equation

$$
y=-9 \mathrm{E}-06 x^{3}+0.001 x^{2}-0.091 x+1.845, R^{2}=0.784
$$

where, $y$ is the saturated $\mathrm{Ks}$ in $\mathrm{cm} \cdot \mathrm{hr}^{-1}$ and $x$ is the \% clay content.

\subsection{Field Capacity (Volume Fraction)}

The FC was determined through DSSAT inbuilt pedo-transfer function, to compare it with derived FC, as shown in following equation. It showed very good estimation with DSSAT values $\left(R^{2}=0.922\right)$, which have been used in the present investigation.

$$
\mathrm{FC}=0.0818+0.07225 * \operatorname{SOC}(\%)+0.00525 * \operatorname{Clay}(\%)+0.00161 * \operatorname{Silt}(\%)
$$

\subsection{Scoring Criteria Used}

Scoring on different attributes was done on 0 - 100 scale. We have allocated the score based on sensitivity to growth and development of plants. The criteria were fixed based on logic and personal experiences. The most dominant factors such as soil salinity, $\mathrm{pH}$, and drainage play an important role in deciding soil health and crop growth and development. The scoring values were 25, 40, 60, $100,90,85,80,80,75,70,60$ and 60 for sand, loamy sand, sandy loam, loam, silt loam, silt, sandy clay, clay loam, silty clay loam, sandy clay, silty clay and clay respectively. Scores assigned for well drained, medium well drained to well drained but surface imperfect drainage, imperfectly drained, poorly drain early, 
poorly drain late and very poorly drain were $100,75,50,30,20$ and 5, respectively. The scoring criteria for other attributes are shown in Table 1 and Figures 1(a)-(d).

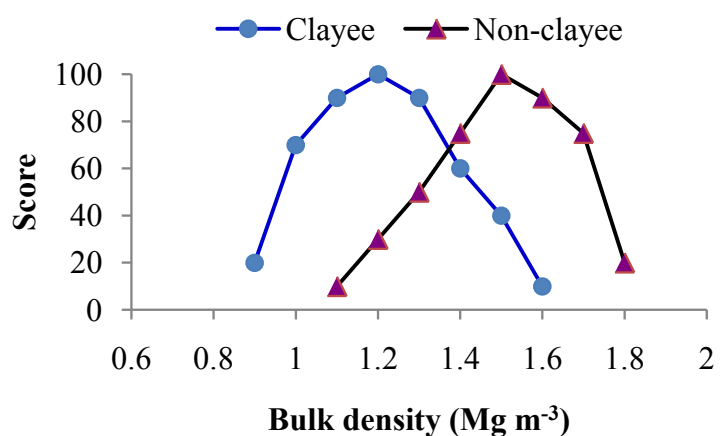

(a)

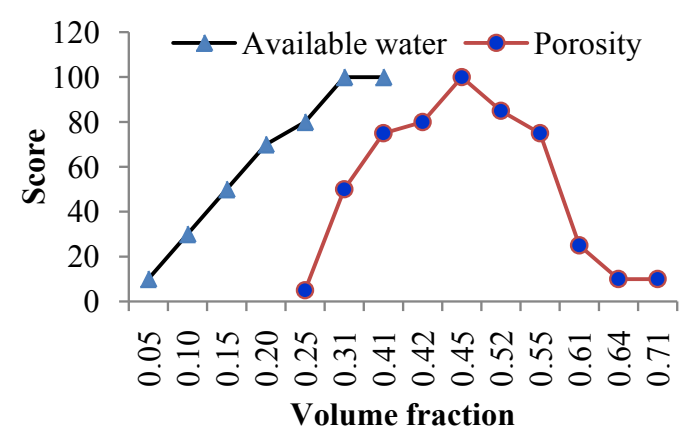

(b)

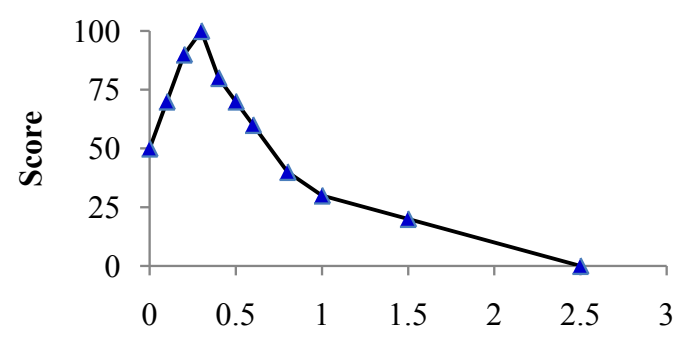

Ks $\left(\mathrm{cm} \mathrm{hr}^{-1}\right)$

(c)

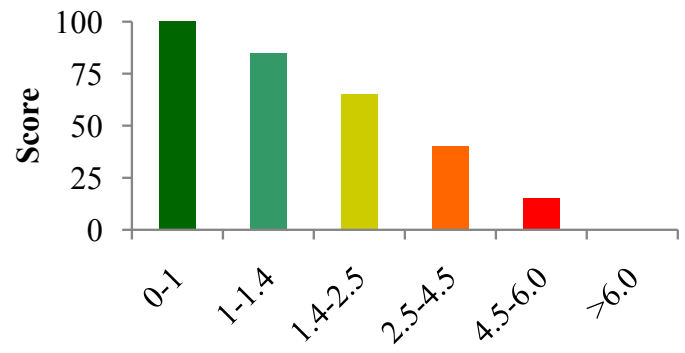

Salinity (dS m $\left.{ }^{-1}\right)$

(d)

Figure 1. Scoring criteria for (a) bulk density, (b) available soil water and porosity, (c) saturated hydraulic conductivity and (d) salinity. 
Table 1. Scoring criteria for different soil attributes.

\begin{tabular}{ccccccccccccc}
\hline $\begin{array}{c}\text { Soil depth } \\
(\mathrm{cm})\end{array}$ & \multicolumn{2}{c}{ Soil pH } & \multicolumn{2}{c}{ SOC $(\%)$} & \multicolumn{2}{c}{$\begin{array}{c}\text { CEC } \\
\left(\mathrm{cmol} \cdot \mathrm{kg}^{-1}\right)\end{array}$} & \multicolumn{2}{c}{$\begin{array}{c}\text { WDCS } \\
(\text { Index })\end{array}$} & \multicolumn{2}{c}{ Slope (\%) } \\
\hline Range & Score & Range & Score & Range & Score & Range & Score & Range & Score & Range & Score \\
$<30$ & 5 & $<4.5$ & 10 & $<0.1$ & 10 & $<5$ & 25 & $<20$ & 100 & $<3$ & 100 \\
$30-50$ & 10 & $4.5-5.0$ & 25 & $0.1-0.3$ & 25 & $5-10$ & 40 & $20-25$ & 90 & $3-8$ & 80 \\
$50-70$ & 30 & $5.0-5.5$ & 40 & $0.3-0.5$ & 50 & $10-20$ & 65 & $25-30$ & 80 & $8-16$ & 60 \\
$70-80$ & 60 & $5.5-6.0$ & 60 & $0.5-0.8$ & 75 & $20-30$ & 75 & $30-35$ & 60 & $16-30$ & 40 \\
$80-115$ & 75 & $6.0-6.7$ & 75 & $0.8-1.2$ & 90 & $30-40$ & 80 & $35-40$ & 50 & $30-45$ & 10 \\
$115-130$ & 80 & $6.7-7.3$ & 100 & $>1.2$ & 100 & $40-50$ & 85 & $40-45$ & 40 & $>45$ & 5 \\
$>130$ & 100 & $7.3-8.0$ & 70 & & & $>50$ & 100 & $45-50$ & 30 & & \\
& & $8.0-8.5$ & 25 & & & & & $>50$ & 20 & & \\
& & $>8.5$ & 5 & & & & & & & & \\
\hline
\end{tabular}

\subsection{Relationship of SQI with Crop Production}

\subsubsection{Production Function (Additive)}

On the basis of 13 attributes, chosen for defining the soil health, additive function was generated to compute wheat yield (five years average over the districts, taken from Bangladesh Bureau of Statistics). The function was generated through multiple regression approach as shown below in which the regression coefficients indicated the sensitivity of each attribute.

$$
Y=\sum_{i=1}^{13} a_{i} * A t t_{i}+A
$$

where, $Y$ is the computed yield $\left(\mathrm{t} \cdot \mathrm{ha}^{-1}\right)$

$a_{i}$ is the regression coefficient (for $i$ th attribute)

$A t t_{i}$ is the attribute $\left(I^{\text {th }}\right)$

$i=1-13$ (attribute number) and $A$ is the constant

\subsubsection{Production Function (Multiplicative)}

Crop growth and development are influenced by different stress factors in diverse ways having variable severity potential. One attribute might be very influential than the others. So, additive function might not be effective in predicting the productivity of a test crop. Thereby, it was thought to deal the inter-attributes stresses in a multiplicative procedure, as given in the equation below:

$$
Y_{r}=A * \pi_{i=1}^{13}\left(A t t_{i}\right)^{\lambda_{i}}
$$

where, $Y_{r}$ is the relative yield (ratio of actual yield to attainable yield)

$\lambda_{i}$ is the power weighted function of $i$ th attribute, $i=1,2,3, \cdots, 13$

$A t t_{i}$ is the attribute $\left(I^{\text {th }}\right)$

and $A$ is the constant

Weighted power coefficients $\left(\lambda_{i}\right)$ were computed based on Equation (7) by taking logarithm. 


$$
\log _{10} Y_{r}=\log _{10} A+\sum_{i=1}^{13} \lambda_{i} * \log _{10} A t t_{i}
$$

Through multiple regression analysis, the values of $\lambda_{I}$ and $A$ were determined. The values of $\lambda_{I}$ can indicate the relative sensitivity of each attributes towards computation of the productivity.

\subsection{Soil Quality Index Determination}

Soil health rating indices were computed through geometric mean calculation in six approaches (discussed later) and compared with PCA using SPSS (version 16). Weightage factor for each principal component (PC) was calculated based on total percentage of variance divided by percentage of cumulative variance [9]. Minimum soil attributes were selected at per Vasu et al. [12], by considering moderate $(0.5$ - 0.75$)$ and strong $(>0.75)$ varimax factor loads. However, soil parameters having strong factor loads were considered for establishing relationship with attained SQI score and grain yields of wheat.

All 13 attributes were considered for geometric means calculation in approach one, as the stress of one attribute influences the others. Since the living system productivity is primarily driven by the most stressed biotic/abiotic factor, the attribute with the lowest rating was considered in approach two. In other approaches, the soil health rating indices were developed by evaluating the geometric means of the lowest rated two, three, four and five attributes for each district.

Geometric mean (GM) score was calculated as follows:

$$
\mathrm{GM}=([\text { Parameter1 }] *[\text { Parameter } 2] *[\text { Parameter3 }] * \ldots *[\text { Parameter13 }])^{1 / 13}
$$

\section{Results}

In terms of texture, the SQI of 50 - 70 group was clay, silty clay and sandy clay dominated soils (35\%). Sandy loam, sandy clay loam, clay loam and silty clay loam represented about $30 \%$ areas of the country (Figure 2(a)). The top scoring group (SQI > 90) was loam in texture that covered about $8.6 \%$ areas. About $21 \%$ soils were with good aggregate stability, but $24 \%$ soils belong to very low aggregate stability group (Figure 2(b)) because of higher silt and sand contents. Almost $21 \%$ soils showed less than $50 \%$ porosity (Figure $2(\mathrm{c})$ ). In terms of BD, nearly $38 \%$ soils belong to $1.5-1.6 \mathrm{Mg} \cdot \mathrm{m}^{-3}$ category (Figure $2(\mathrm{~d})$ ) and the rest in several other groups. In most soils (about 50\%), available water was high (Figure 2(e)) and about $15 \%$ had the least water availability. About $41 \%$ soils showed $\mathrm{Ks}$ of $0.5-1.5 \mathrm{~cm} \cdot \mathrm{hr}^{-1}$ and the others were $0.1-0.4 \mathrm{~cm} \cdot \mathrm{hr}^{-1}$ (Figure 2(f)). The CEC score was $<20$ in less than one percent area of Bangladesh; 20 $50,50-70$ and $>70$ scores in about $40 \%, 36 \%$ and $22 \%$ soils, respectively (Figure $2(\mathrm{~g}))$. Soil depths in most cases $(\sim 71 \%)$ were high and only $10 \%$ of them belong to shallow depth category (Figure $2(\mathrm{~h})$ ). Fifty percent soils scored $>85$ for SOC contents that had more than $1.2 \%$ organic C (Figure $3(\mathrm{a})$ ), others were poor in SOC. Almost $40 \%$ soils belong to good soil $\mathrm{pH}$ ranges (Figure $3(\mathrm{~b})$ ), although 
critical soil $\mathrm{pH}$ in the lower range covers about $26 \%$ areas in Bangladesh. There are very strongly acid soils in about $15 \%$ areas, $\mathrm{pH} 4.0-5.5$ in $22.3 \%$, pH 7.5 8.25 in $34.2 \%$ and $>8.25 \mathrm{pH}$ in $28.1 \%$ areas of Bangladesh.

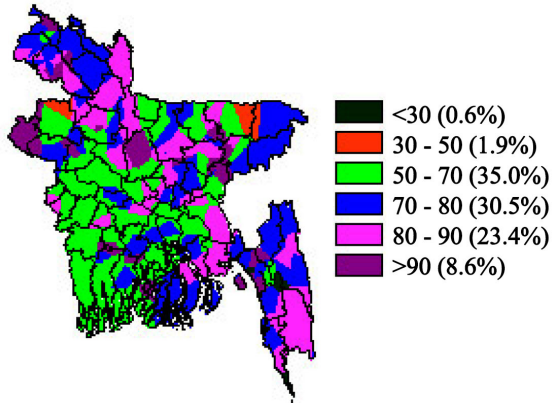

(a)

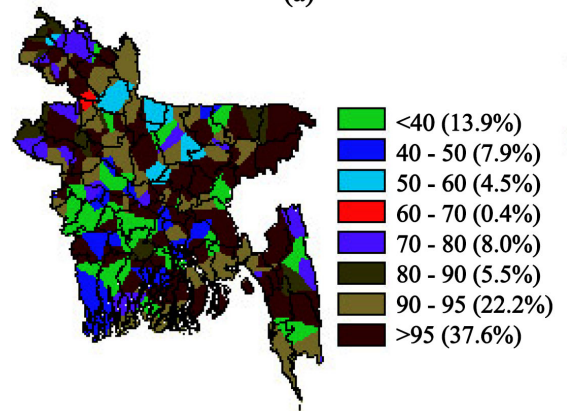

(c)

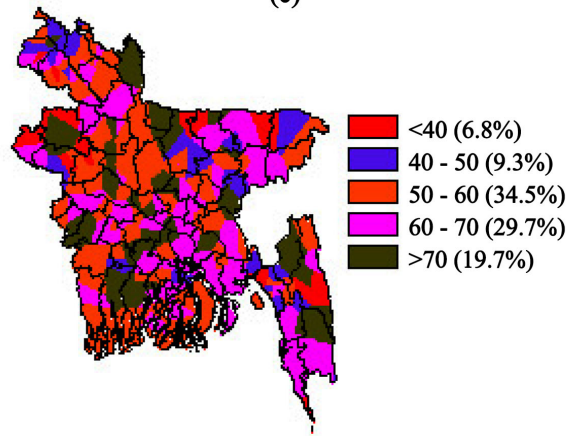

(e)

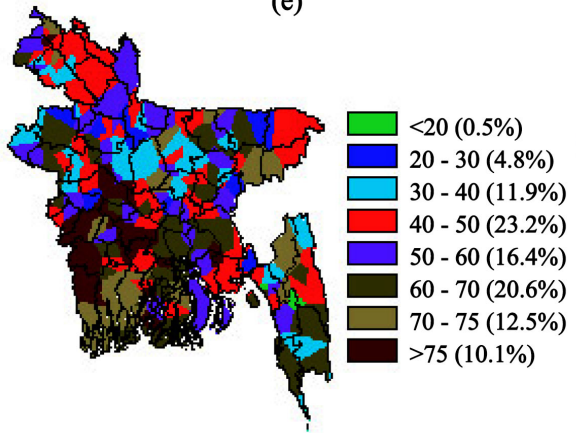

(g)

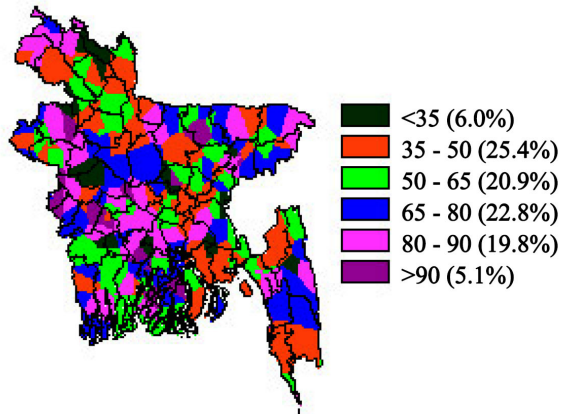

(b)

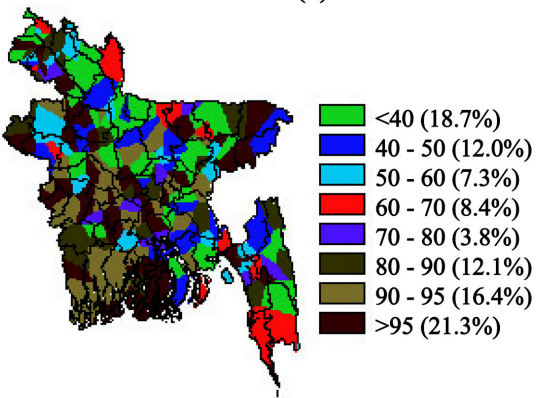

(d)

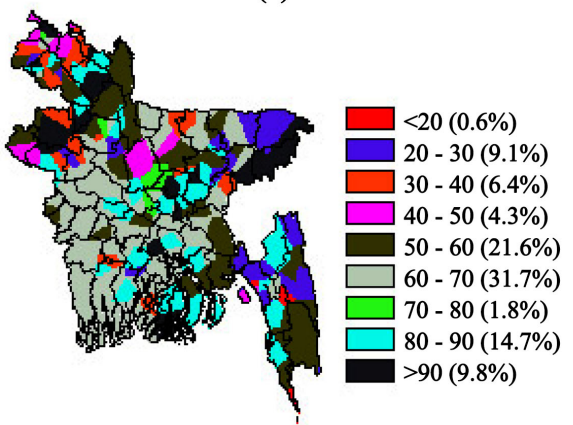

(f)

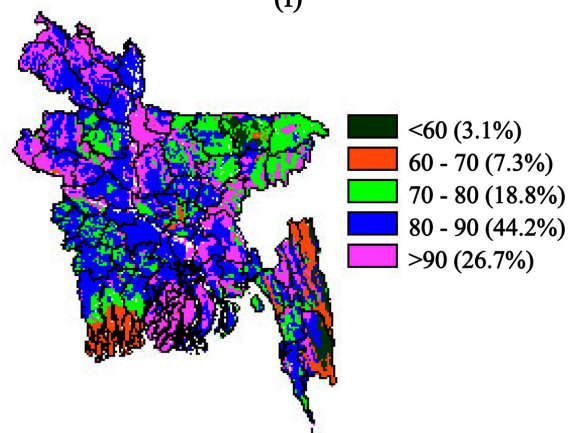

(h)

Figure 2. Spatial distribution of scoring for (a) soil texture, (b) aggregate stability, (c) porosity, (d) bulk density, (e) available water, (f) saturated hydraulic conductivity, (g) CEC and (h) depth in Bangladesh; figures in the parentheses indicate percent of total 13.83 million ha. 

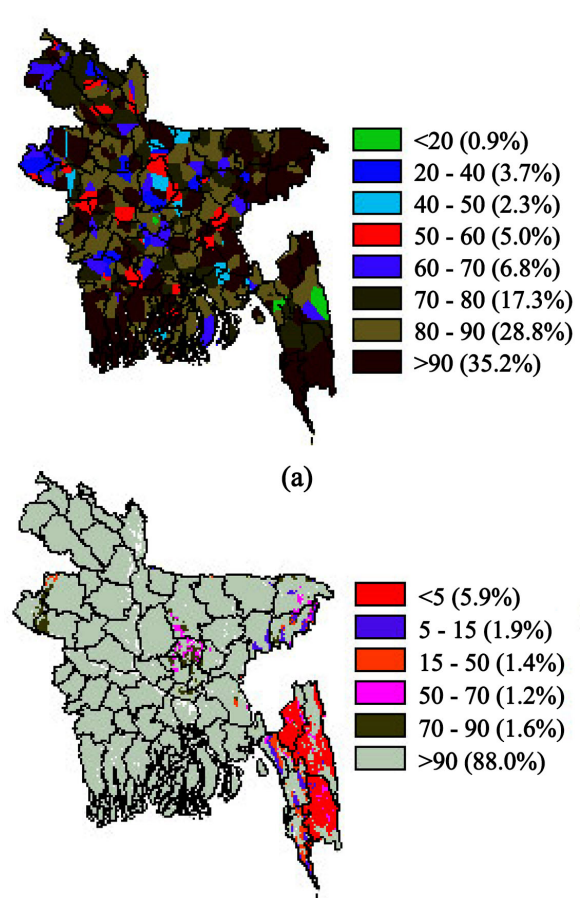

(c)

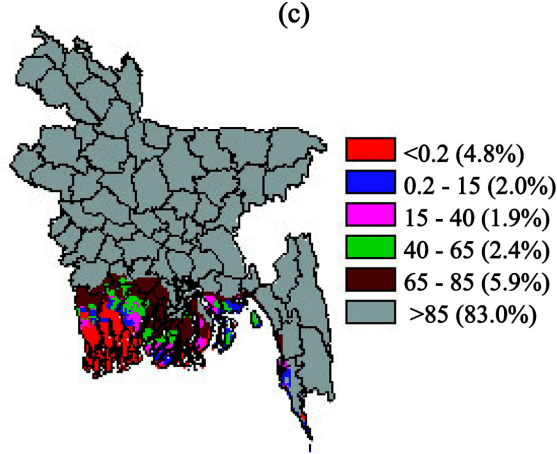

(e)

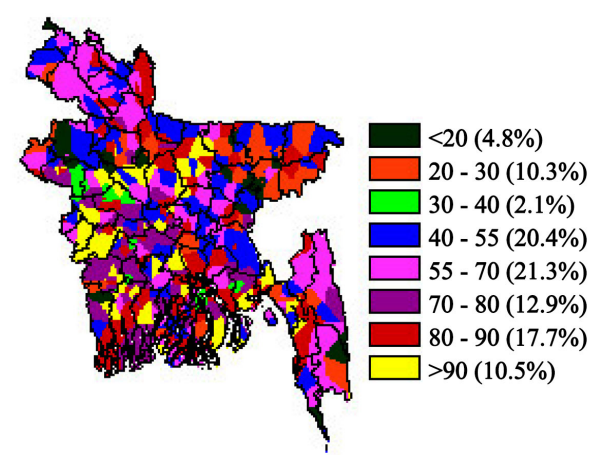

(b)

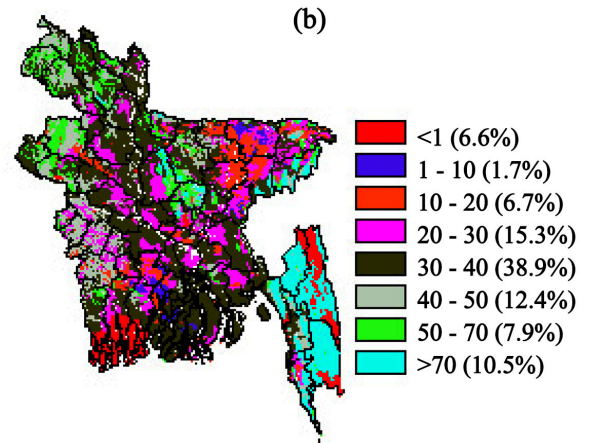

(d)

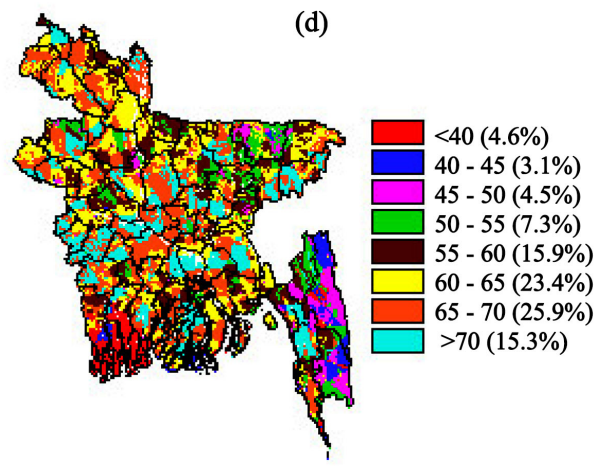

(f)

Figure 3. Spatial distribution of scoring for (a) SOC, (b) soil pH, (c) slope, (d) drainage, (e) salinity and ( $f$ ) soil health quality index in Bangladesh; figures in the parentheses indicate percent of total 13.83 million ha.

More than $80 \%$ soils are flat in Bangladesh (Figure 3(c)) and only $6 \%$ belong to steep slope areas. Well drained soils comprised only about $10 \%$ in Bangladesh that scored $>70 \%$ (Figure $3(\mathrm{~d})$ ). Most soils suffer from drainage problems depending on crop growing season and rainfall patterns. Major soils (83\%) are non-saline $\left(0-1.0 \mathrm{dS} \cdot \mathrm{m}^{-1}\right.$ in Bangladesh (Figure $\left.3(\mathrm{e})\right)$ and about $4.8 \%$ face salinity problem of $>6.0 \mathrm{dS} \cdot \mathrm{m}^{-1}$.

Considering all tested soil quality parameters, about $64.6 \%$ soils scored more than $60 \%$ and $23.2 \%$ in the category of $50-60$ and about $12.3 \%$ in the least scoring groups (Figure $3(\mathrm{f})$ ). When the relationship of SQI was done with productivity, the predictability was relatively lower. Considering all the test attributes, soil health in relation to crop's response was not satisfactory. The least scoring range was increasing with time due to enhanced industrial pollution, sa- 
linity rise and urbanization (data not reported). The best soil group (scored > 70) covers only about $15 \%$ areas in the country having potential for growing high value crops.

The attained scores were evaluated against average wheat grain yields of 2011-2015, considering all soil tested attributes, two most minimum scoring attributes and one most minimum scoring attribute (Figures 4(a)-(c)) and it could be concluded that predictability increased when we take the attribute that highly impair crop growth and development.

Grain yields of wheat as estimated from multiple regressions considering all tested attributes (Equation \# 10) can explain about $44 \%$ of its yield variability. Computed and observed grain yields of wheat showed good relationship with soil health score (Figure 5(a)).

$$
\begin{aligned}
Y= & 1.617773+0.000154 * \text { Salinity }-0.0016 * \text { Available water } \\
& +0.000175 * \mathrm{BD}+0.001043 * \mathrm{CEC}-0.0182 * \text { Soil depth } \\
& -0.0179 * \mathrm{SOC}+0.001095 * \mathrm{pH}-0.00708 * \text { Porosity } \\
& -0.00432 * \mathrm{Ks}+0.039457 * \text { Slope }-0.00531 * \text { Texture } \\
& +0.001784 * \mathrm{WDCS}+0.0324688 * \text { Drainage; } R^{2}=0.4385 *\left(\mathrm{P}_{0.001}\right)
\end{aligned}
$$

Additive multiplicative response function, as established from the equation number 10, is more sensitive and showed better relationship between estimated and observed wheat yields (Figure 5 (b) when compared to multiple regression approach.

$$
\begin{aligned}
& Y=99.13 * \text { Salinity }^{-0.15233} * \text { Available water }{ }^{0.1436} * \mathrm{BD}^{-0.02492} \\
& \text { * } \mathrm{CEC}^{0.093307} * \text { Soil depth }{ }^{-1.37645} * \mathrm{SOC}^{-0.64887} * \mathrm{pH}^{0.013339} \\
& \text { * Porosity }{ }^{-0.16367} * \mathrm{Ks}^{-0.15728} * \text { Slope }^{1.6413459} * \text { Texture }^{-0.11644} \\
& \text { * } \mathrm{WDCS}^{-0.02297 * \text { Drainage }}{ }^{0.831774} ; R^{2}=0.62 * *\left(\mathrm{P}_{0.001}\right)
\end{aligned}
$$

For comparative evaluation of six soil health rating indices, the values derived in each district was evaluated against wheat yields (average over five years), and the correlation matrix was drawn. From the correlation matrix, it could be concluded that if we take one or two attributes with most limiting factor for crop growth and development, the coefficient of predictability of wheat yields improves (Table 2).

We also employed PCA to find out minimum soil attributes that effectively influence soil health scoring index. It was found that about $45.5 \%$ of variations in soil health rating could be explained if PC1 and PC2 are considered (Table 3). Considering strongly loaded factors, the SOC (0.78), WDCS (0.868), Ks (0.926), $\mathrm{BD}(0.754)$, drainage (0.823) and slope (-0.904) were the important attributes for soil health determination of which BD and WDCS represented PC1, slope and drainage PC2 and Ks and SOC represented PC3. However, the PCA based selected six attributes were able to explain about $36 \%$ yield variability of wheat crop in Bangladesh $\left(y=-0.4754+0.0024^{\star} \mathrm{BD}-0.0103^{*} \mathrm{SOC}-0.0061^{\star} \mathrm{Ks}+\right.$ $0.0304^{\star}$ Slope $+0.0061^{\star}$ WDCS $+0.0208^{\star}$ Drainage; $\left.R^{2}=0.3634^{* *} ; \mathrm{P}_{0.001}\right)$. 


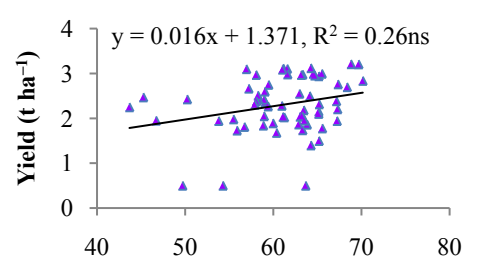

(a)

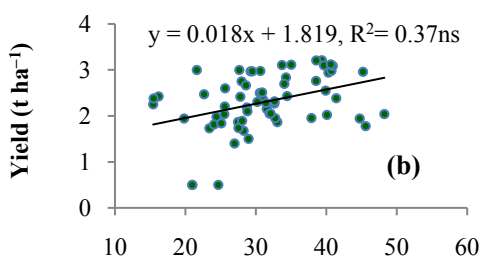

(b)

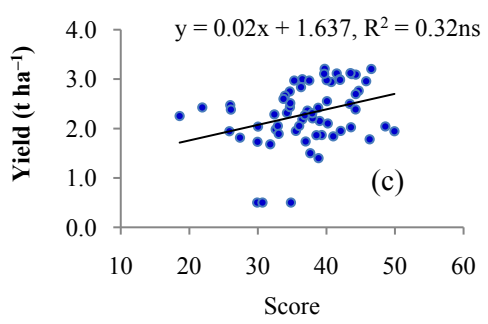

(c)

Figure 4. Relationships of wheat yield with (a) all soil tested attributes, (b) two most minimum attributes and (c) one most minimum attribute for wheat growing districts in Bangladesh (ns = non-significant).

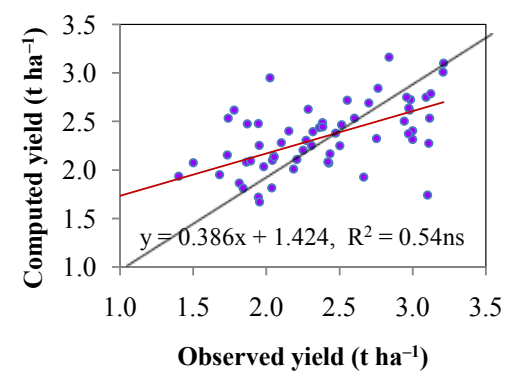

(a)

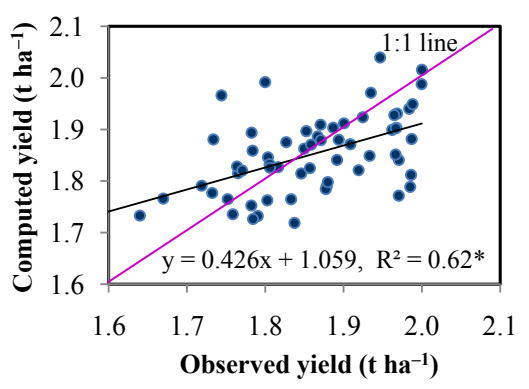

(b)

Figure 5. Relationship of computed verses observed grain yield of wheat, as determined by integrating all attributes through (a) multiple regression and (b) additive multiple regression approaches ( $\mathrm{ns}=$ non-significant; ${ }^{*}=$ significant at $5 \%$ level of probability). 
Table 2. Correlation matrix showing relationships of soil health score with wheat yield.

\begin{tabular}{|c|c|c|c|c|c|c|c|}
\hline & Approach 1 & Approach 2 & Approach 3 & Approach 4 & Approach 5 & Approach 6 & Yield \\
\hline Approach 1 & 1 & & & & & & \\
\hline Approach 2 & $0.512853 \mathrm{~ns}$ & 1 & & & & & \\
\hline Approach 3 & $0.657342^{*}$ & $0.838989^{* *}$ & 1 & & & & \\
\hline Approach 4 & $0.679636^{*}$ & $0.668905^{\star}$ & $0.946657^{\star *}$ & 1 & & & \\
\hline Approach 5 & $0.668994^{\star}$ & $0.553923 \mathrm{~ns}$ & $0.874866^{\star *}$ & $0.979727^{\star *}$ & 1 & & \\
\hline Approach 6 & $0.665833^{\star}$ & $0.482331 \mathrm{~ns}$ & $0.816641^{\star *}$ & $0.949475^{\star *}$ & $0.990784^{* *}$ & 1 & \\
\hline Yield & $0.266267 \mathrm{~ns}$ & $0.373025 \mathrm{~ns}$ & $0.318145 \mathrm{~ns}$ & $0.271349 \mathrm{~ns}$ & $0.246809 \mathrm{~ns}$ & $0.230201 \mathrm{~ns}$ & 1 \\
\hline
\end{tabular}

Table 3. Principal components, Eigenvalues and variances.

\begin{tabular}{cccccc}
\hline & PC1 & PC2 & PC3 & PC4 & PC5 \\
\hline Eigenvalue & 3.909 & 2.006 & 1.400 & 1.119 & 1.055 \\
\% Variance & 30.069 & 15.430 & 10.770 & 8.608 & 8.112 \\
\% Cumulative variance & 30.069 & 45.499 & 56.269 & 64.877 & 72.988 \\
Weightage factor & 0.412 & 0.211 & 0.146 & 0.118 & 0.111 \\
\hline
\end{tabular}

\section{Discussion}

We have chosen 13 attributes for SQI development of which soil salinity and drainage play a pivotal role for arable crop production in Bangladesh; but Velasquez et al. [23] used 50 soils properties, the highest number of soil attributes, to develop a general SQI that might not be suitable for many researchers in developing countries. However, reports on SQI with fewer attributes are also available. The soil management frame work based on SQI considered 13 parameters from physical, chemical and biological factors [24], but they ignored soil depth, which is important for many regions of the world. Laishram et al. [25] reported 12 soil indicators for soil health assessment. They have included suspected pollutants and soil respiration-important points, but not easily available in many developing countries. Though works on soil pollutions are on-going sporadically, adequate data on soil biology are not available in this part of the world. So, we were unable to include those factors. We have considered SOC that actually dictates microbial activities [26] [27] and acts as a source of plant nutrients [28] [29]. Loganathan and Narendiran [29] also reported that soil organic matter and aggregate stability are important indicators for soil quality assessment. Different statistical tools, such as multiple correlations, PCA, star plots, factor and cluster analyses are performed for SQI determination [30] [31]. We have utilized additive and multiplicative production function through regression analysis to deal with inter-attributes interactions and six approaches for geometric mean score determination and finally correlated with wheat crop yields to reveal a new methodology of soil health quality determination.

Soils of Bangladesh are mostly flat and dominated by silt and clay that influ- 
ence porosity, $\mathrm{BD}, \mathrm{CEC}$, water holding capacity, drainage, nutrient availability, $\mathrm{pH}$, etc. These are also important soil health determinants [32]. Effective soil depth is a good indicator of soil available water and nutrients, but not much is known for its long term benefit [31]. Our top scoring soil was loamy in texture (Figure 2(a)), having good depth with 18\% - 25\% clay, 5\% - 40\% sand and 5.6 $6.5 \mathrm{pH}$. These properties are not universal and vary depending on scoring methods and regions of the world. Gruver and Weil [33] found good soil rating with $10.5 \%$ clay and $45 \%$ sand having a $\mathrm{pH}$ of 6.5 . Soil $\mathrm{pH}$ greatly influences salinization, electrical conductivity, exchangeable sodium $(\mathrm{Na})$ and structural stability [34], nutrient availability [31]. In general, SOC, porosity and aggregate stability influence SQI values [35]. We have also found good soil aggregate stability score with higher SOC that ultimately govern soil erosion, surface crapping and directly or indirectly soil fertility and crop productivity [36].

Final soil health score was divided into eight groups (Figure 3(f)), to be used effectively as a benchmark for growing different crops. In literature we have found less grouping viz. five for Cornel Soil Health Assessment [1] that might be suitable in the USA because of climate and edaphic factors. Since soil quality rating varies depending on crops to be grown, a good rated soil should have direct linkages with crop productivity. So, the most sensitive soil parameters need to be identified that impairs crop growth and development severely, which has been delineated in this report. Similar views were also expressed by Andrews et al. [37]. The tolerance ability of a crop to certain stress makes it a better choice for consideration to be cultivated in a particular region. For example, rice can tolerate salinity of $4-6 \mathrm{dS} \cdot \mathrm{m}^{-1}$, water stagnation and even submergence tolerant varieties are available [38] indicating that they can be cultivated in most places of Bangladesh except in the areas having the least soil health ratings.

Our efforts to minimize data set requirements for SQI determination though PCA analysis and its relationships with grain yields of wheat showed lesser correlation coefficients for BD (0.10074), SOC (0.09274), Ks (0.17210), slope (0.17525), WDCS $(0.49144)$ and drainage $(-0.21033)$ compared to geometric mean approach (Table 2). Moreover, wheat grain yields as estimated from PCA derived strong loaded factors showed inferior relationships than multiplicative regression function response. Similar findings were also reported by Vasu et al. [12]. They reported that weighted index SQIs were better correlated with crop yields than additive SQIs for PCA.

The prediction of wheat yield from the soil health rating index appears to be low, as we could understand that the yield also depends on other biotic and abiotic stresses such as temperature, insects, diseases, inputs and agronomic management practices in different parts of the country. Moreover, all regions are not suitable for growing wheat, because of unfavorable ecology and unsuitability of land, although efforts are underway to grow wheat in more areas of Bangladesh. Besides, dynamic soil properties may change within hours or it may take a period of decades depending on many factors of particular localities and thus good relationships between SQI and grain yield might not be established easily in 
some cases.

The efficacy of SQI depends on its acceptance by the end users. Farmers/producers generally want a simple technique as was found in the USA, where farmers related their scoring with soil carbon and soil structure effectively [33]. Soil color, as influenced by organic matter content and texture are also good SQI from the farmer's point of view [39]. In this paper, the aim was primarily to develop a methodology to derive soil health rating index by including physical, chemical and physico-chemical characters of soils. Our efforts clearly indicate that SQI developed for Bangladesh can be utilized for proper utilization of soil resources in terms of crop zoning and delineation of management options for growing different crops.

\section{Conclusion}

A method for soil quality assessment has been developed for Bangladesh, which would be applicable for similar environments around the globe. Thirteen soil attributes were used in determining SQI. Attribute wise, the lowest score (say 1, $5,10,20$, etc.) was assigned for the most adverse soil conditions within the scale of 0 - 100 and the gradually higher score was provided for comparatively favorable crop growing environments. Different approaches for deriving SQI, by dealing with 13 attributes (altogether, most stressed one, most stressed two attributes, six attributes through PCA) by following additive and multiplicative regression fits. The indices were related to wheat yields (five years average). It was clear that multiplicative approach provides better predictability of yield estimates. Also, if we take all 13 tested attributes, the performance is not satisfactory, compared to one/two most attributes that severely affect crop growth and development. Through PCA, six attributes were identified for soil health assessment, but their use for yield estimates could not perform better than the multiplicative regression approach. In this paper, we have shown the methodology for SQI determination and established linkage with wheat yields satisfactorily. This methodology could be useful in irrigation scheduling, nutrients management options, and resource conservation technologies for sustained agricultural production.

\section{Acknowledgements}

We greatly acknowledge the financial support for this research activity of Krishi Gobeshona Foundation (KGF) through modeling climate change impact assessment project in Bangladesh (CRP-II).

\section{Conflicts of Interest}

The authors declare no conflicts of interest regarding the publication of this paper.

\section{References}

[1] Gugino, B.K., Idowu, O.J., Schindelbeck, R.R., van Es, H.M., Wolfe, D.W., Moe- 
bius-Clune, B.N., Thies, J.E. and Abawi, G.S. (2009) Cornel Soil Health Assessment Manual. 2nd Edition, Cornell University, New York, 1-57.

[2] Ohio Soil Health Card (OSHC) (2004) Sustainable Agriculture Fact Sheet Series, SAG-1. The Ohio State University, Columbus, $\mathrm{OH}$.

[3] Karlen, D.L., Andrews, S.S., Wienhold, B.J. and Zobek, T.M. (2008) Soil Quality Assessment: Past, Present and Future. Journal of Integrative Bioscience, 6, 3-14.

[4] Larsen, W.E. and Pierce, F.J. (1994) The Dynamics of Soil Quality as a Measure of Sustainable Management. In: Doran, J.W., et al., Eds., Defining Soil Quality for a Sustainable Environment, SSSA, Madison, WI, 37-52.

[5] Doran, J.W. and Parkin, T.B. (1994) Defining and Assessing Soil Quality. In: Doran, J.W., et al., Eds., Defining Soil Quality for a Sustainable Environment, ASA and SSSA, Madison, WI, 2-21. https://doi.org/10.2136/sssaspecpub35.c1

[6] Karlen, D.L., Wollenhaupt, N.C., Erbach, D.C., Berry, E.C., Swan, J.B., Eashand, N.S. and Jordahl, J.L. (1994) Crop Residue Effects on Soil Quality Following 10 Years of No-Till Corn. Soil Tillage \& Research, 31, 149-167.

https://doi.org/10.1016/0167-1987(94)90077-9

[7] Andrews, S.S., Karlen, D.L. and Mitchel, J.P. (2002) A Comparison of Soil Quality Indexing Methods for Vegetable Production Systems in Northern California. Agriculture, Ecosystems \& Environment, 90, 25-45. https://doi.org/10.1016/S0167-8809(01)00174-8

[8] Armenise, E., Redmile, G.M.A., Stellacci, A.M., Ciccarese, A. and Rubino, P. (2013) Developing a Soil Quality Index to Compare Soil Fitness for Agricultural Use under Different Managements in the Mediterranean Environment. Soil Tillage \& Research, 130, 91-98. https://doi.org/10.1016/j.still.2013.02.013

[9] Ray, S.K., Bhattacharyya, T., Reddy, K.R., Pal, D.K., Chandran, P., Tiwary, P. and Mandal, D.K. (2014) Soil and Land Quality Indicators of the Indo-Gangetic Plain of India. Current Science, 107, 1470-1486.

[10] Moncada, M.P., Gabriel, D. and Comelis, W.M. (2014) Data-Driven Analysis of Soil Quality Indicators Using Limited Data. Geoderma, 235-236, 271-278. https://doi.org/10.1016/j.geoderma.2014.07.014

[11] Sparling, G.P., Schipper, L.A., Bettjeman, W. and Hill, R. (2004) Soil Quality Monitoring in New Zealand: Practice Lessons from a 6-Year Trial. Agriculture, Ecosystems \& Environment, 104, 523-534. https://doi.org/10.1016/j.agee.2004.01.021

[12] Vasu, D, Singh, S.K., Ray, S.K., Duraisami, V.P., Tiwary, P., Chandran, P., Nimkar, A.M. and Anantwar, S.G. (2016) Soil Quality Index (SQI) as a Tool as a Tool to Evaluate Crop Productivity in Semi-Arid Deccan Plateau, India. Geoderma, 282, 70-79. https://doi.org/10.1016/j.geoderma.2016.07.010

[13] Mukherjee, A. and Lal, R. (2014) Comparison of Soil Quality Index Using Three Methods. PLoS ONE, 9, e105981. https://doi.org/10.1371/journal.pone.0105981

[14] Food and Agriculture Organization (FAO) (1976) A Framework for Land Evaluation. Food and Agriculture Organization of the United States, Soil Bulletin No. 32, FAO, Rome.

[15] Storie, R. (1978) Storie Index Soil Rating. University of California, Special Publication 3203, Oakland, CA.

[16] Sys, C., Ranst, E.V. and Debaveye, J. (1991) Land Evaluation and Crop Production Calculations. General Administration for Development Cooperation, Brussels, 40-80.

[17] Askari, M.S. and Holden, N.M. (2015) Quantitative Soil Quality Indexing of Tem- 
perate Arable Management. Soil Tillage \& Research, 150, 57-67.

https://doi.org/10.1016/j.still.2015.01.010

[18] de Paul Obade, V. and Lal, R. (2016) Towards a Standard Technique for Soil Quality Assessment. Geoderma, 265, 96-102.

https://doi.org/10.1016/j.geoderma.2015.11.023

[19] Adhikary, P.P., Chakraborty, D., Kalra, N., Sachdev, C.B., Patra, A.K., Kumar, S., Tomar, R.K., Chandna, P., Raghav, D., Agrawal, A. and Sehgal, M. (2008) Peo-Transfer Functions for Predicting the Hydraulic Properties of Indian Soils. Australian Journal of Soil Research, 46, 476-484. https://doi.org/10.1071/SR07042

[20] Kalra, N., Aggarwal, P.K., Bandyopadhyay, S.K., Malik, A.K. and Kumar, S. (1994) Prediction of Moisture Retention and Transmission Characteristics from Soil Texture of Indian Soils. In: Lansigan, F.P., Bouman, B.A.M. and van Laar, H.H., Eds., Agro-Ecological Zonation, Characterization and Optimization of Rice Based Cropping Systems, SARP Research Proceedings, AB-DLO and TPE, Wageningen, 26-35.

[21] Haque, M.M., Biswas, J.C., Akter, M., Maniruzzaman, M. and Kabir, M.S. (2019) Carbon Budget and Aggregate Stability of Paddy Soil under Continuous Organic Amendment. Communications in Soil Science and Plant Analysis, 50, 1829-1837.

[22] Sung, C.T.B. (2012) Aggregate Stability of Tropical Soils in Relation to Their Organic Matter Constituents and Other Soil Properties. Pertanika Journal of Tropical Agricultural Science, 35, 135-148.

[23] Velasquez, E., Lavelle, P. and Andrade, M. (2007) GISW, a Multifunctional Indicator of Soil Quality. Soil Biology and Biochemistry, 39, 3066-3080. https://doi.org/10.1016/j.soilbio.2007.06.013

[24] Veum, K., Kremer, R. and Goyne, K. (2013) Assessing Soil Health in Missouri Agricultural Soils. Soil Health Workshop, Bradford Extension and Research Center.

[25] Laishram, J., Saxena, K.G., Maikhuri, R.K. and Rao, K.S. (2012) Soil Quality and Soil Health: A Review. International Journal of Ecology and Environmental Sciences, 38, 19-37.

[26] Gadja, A.M., Doran, J.W., Wienhold, B.J., Kettler, T.A., Pikul, J.L. and Cambardella, C.A. (2001) Soil Quality Evaluations of Alternative and Conventional Management Systems in the Great Plains. In: Lal, R., Kimble, F.F., Follet, R.F. and Steward, B.A., Eds., Methods of Assessment of Soil Carbon, CRC Press, Boca Raton, FL, 361-400.

[27] Komatsuzaki, M. and Ohta, H. (2007) Soil Management Practices for Sustainable Agro-Ecosystems. Sustainability Science, 2, 103-120. https://doi.org/10.1007/s11625-006-0014-5

[28] Dumaniski, J. and Pieri, C. (2000) Land Quality Indicators: Research Plan. Agriculture, Ecosystems \& Environment, 81, 93-102. https://doi.org/10.1016/S0167-8809(00)00183-3

[29] Loganathan, M. and Narendiran, J. (2014) Characterization of Soil Quality Indicators: A Study. Journal of Global Biosciences, 3, 586-592.

[30] Bachmann, G. and Kinzel, H. (1992) Physiological and Ecological Aspects of the Interactions between Plant Roots and Rhizosphere Soil. Soil Biology \& Biochemistry, 24, 543-552. https://doi.org/10.1016/0038-0717(92)90079-D

[31] Doran, J.W. and Parkin, T.B. (1996) Quantitative Indicators of Soil Quality: A Minimum Data Set. In: Doran, J.W., Ed., Methods for Assessing Soil Quality, SSSA Special Publication No. 49, Soil Science Society of America, Madison, WI, 25-35. https://doi.org/10.2136/sssaspecpub49.c2

[32] Hsiao, C.J., Gretchen, S., Charles, R., Zeglin, L. and Hettiarachchi, G. (2017) Key 
Components of Healthy Soils and Their Role in Crop Production. Kansas Agricultural Experiment Station Research Reports, 3, 1-4.

https://doi.org/10.4148/2378-5977.1385

[33] Gruver, J.B. and Weil. R.R. (2007) Farmer Perceptions of Soil Quality and Their Relationship to Management-Sensitive Soil Parameters. Renewable Agriculture and Food Systems, 22, 271-281. https://doi.org/10.1017/S1742170507001834

[34] Rengasamy, P. and Olsson, K.A. (1991) Sodicity and Soil Structure. Australian Journal of Soil Research, 29, 935-952. https://doi.org/10.1071/SR9910935

[35] Gelaw, A.M., Singh, B.R. and Lal, R. (2015) Soil Quality Indices for Evaluating Smallholder Agricultural Land Uses in Northern Ethiopia. Sustainability, 7, 2322-2337. https://doi.org/10.3390/su7032322

[36] Cooper, J. (2011) Soil Structure, Management and Effect on Nutrient Availability and Crop Production. Organic Producer Conference, Facing Current and Future Challenges, Newcastle University, 17 January 2011.

http://www.ksre.ksu.edu/fieldday/kids/soil_pit/soil_structure.htm

[37] Andrews, S.S., Karlen, D.L. and Cambardella, C.A. (2004) The Soil Management Assessment Framework: A Quantitative Evaluation Using Case Studies. Soil Science Society of America Journal, 68, 1945-1962.

[38] Bangladesh Rice Research Institute (BRRI) (2017) Modern Rice Cultivation. 20th Edition, BRRI, Gazipur, 1-88.

[39] Mairura, F.S., Mugendi, D.N., Mwanje, J.I., Ramisch, J.J., Mbugua, P.K. and Chianu, J.N. (2007) Integrating Scientific and Farmer's Evaluation of Soil Quality Indicators in Central Kenya. Geoderma, 139, 134-143.

https://doi.org/10.1016/j.geoderma.2007.01.019 